\title{
INTIMATE PARTNER VIOLENCE AND RECEPTIVE SYRINGE SHARING AMONG WOMEN WHO INJECT DRUGS IN INDONESIA: A RESPONDENT-DRIVEN SAMPLING STUDY
}

\author{
Claudia Stoicescua,1 \\ Lucie D. Cluvera,b \\ Thees F. Spreckelsen ${ }^{\mathrm{a}}$ \\ Mietta M. Mahananic,d \\ Rima Ameilia ${ }^{e, f}$
}

\section{Author affiliations:}

${ }^{a}$ Centre for Evidence-Based Intervention, University of Oxford, Oxford, United Kingdom.

${ }^{\mathrm{b}}$ Department of Psychiatry and Mental Health, University of Cape Town, Cape Town, South Africa.

${ }^{c}$ Faculty of Public Health, University of Indonesia, Depok, Indonesia.

${ }^{d}$ HIV/AIDS Research Centre, Atma Jaya University, Jakarta, Indonesia.

e Department of Criminology, University of Indonesia, Depok, Indonesia.

${ }^{\dagger}$ Criminology Program, Budi Luhur University, Jakarta, Indonesia.

\section{${ }^{1}$ Corresponding Author}

Centre for Evidence-Based Intervention, University of Oxford

Barnett House, 32 -37 Wellington Square

Oxford OX1 2ER.

Telephone: +44(0)1865 270325; Fax: +44(0)1865 270324

E-mail: claudia.stoicescu@spi.ox.ac.uk; claudia.stoicescu@gmail.com

Conflicts of Interest: The authors have no conflicts of interest to disclose.

Running title: IPV and receptive syringe sharing among women who inject drugs 
INTIMATE PARTNER VIOLENCE AND RECEPTIVE SYRINGE SHARING AMONG WOMEN WHO INJECT DRUGS IN INDONESIA: A RESPONDENT-DRIVEN SAMPLING STUDY

\section{ABSTRACT}

Background: Intimate partner violence (IPV) and HIV are overlapping public health problems that disproportionately affect women who inject drugs. Little is known about the relationship between IPV and HIV-related unsafe injecting practices among women in lowand middle-income settings. This study investigated whether IPV victimisation was associated with increased odds of receptive syringe sharing among women who inject drugs in Indonesia.

Methods: Respondent-driven sampling (RDS) was used to recruit 731 women aged $\geq 18$ years, injecting drugs in the preceding 12 months, and residing in Greater Jakarta or Bandung, West Java. Population estimates were derived using the RDS-II estimator. Multivariate logistic regressions assessed relationships between different forms of pastyear IPV (i.e. psychological abuse, physical and/or injurious assault, forced sex) and receptive syringe sharing, controlling for city differences and sociodemographic cofactors.

Results: Overall, $21.1 \%$ of participants reported engaging in past-month receptive syringe sharing. In multivariate analyses controlling for all forms of IPV, receptive syringe sharing was significantly positively associated with experiencing psychological abuse $(O R=1.86$; $95 \% \mathrm{Cl}=1.06,3.24 ; \quad \mathrm{p}=0.030)$, physical and/or injurious assault (OR=1.73; 95\% $\mathrm{Cl}=1.04,2.89 ; \mathrm{p}=0.034$ ), and several covariates: injecting pharmaceuticals only (versus heroin only) $(\mathrm{OR}=3.58 ; 95 \% \mathrm{Cl}=1.66,7.69 ; \mathrm{p}=0.001)$, experiencing unstable housing and/or homelessness (OR=2.89; 95\% $\mathrm{Cl}=1.41,5.95 ; \mathrm{p}=0.004)$, and residing in Bandung, West Java (versus Greater Jakarta) $(\mathrm{OR}=2.33 ; 95 \% \mathrm{Cl}=1.40,3.90 ; \mathrm{p}=0.001)$.

Conclusion: IPV is a significant risk factor for HIV-related injecting risk among women who inject drugs in Indonesia. These findings indicate the urgent need to scale up harm 
reduction interventions and align existing programs with IPV prevention and support services, with specific efforts targeting the needs of female injectors. 


\section{INTRODUCTION}

Unsafe injecting drug use is a major driver of the global HIV epidemic, accounting for one third of new HIV infections outside of sub-Saharan Africa (UNAIDS, 2014). Systematic review evidence suggests that women who inject drugs bear a disproportionate burden of HIV infections compared to male injectors (Des Jarlais, Feelemyer, Modi, Arasteh, \& Hagan, 2012). Yet, until recently, women who inject drugs have remained largely unrecognised in research and intervention development (El-Bassel \& Strathdee, 2015).

Asia is home to $3-5$ million people who inject drugs, representing the highest concentration of any region globally (Stone 2015). An estimated one in three people who inject drugs in Asia are female (Larney, Mathers, Poteat, Kamarulzaman, \& Degenhardt, 2015). Regional HIV prevalence among people who inject drugs is $17 \%$, and HIV incidence in this population is increasing (Stone, 2016). Among national samples of women who inject drugs, HIV rates range from $6.4 \%$ in China to approximately $30 \%$ in Malaysia, Philippines and Thailand (Larney et al., 2015).

Indonesia is faced with an expanding HIV epidemic concentrated among key affected populations (Indonesian National AIDS Commission, 2014). People who inject drugs bear a disproportionate burden of HIV, which affects more than $50 \%$ of injectors in the capital, Jakarta (UNAIDS, 2014). Although national-level HIV prevalence rates are not sex-disaggregated, qualitative research suggests that HIV-related risk behaviours among women who inject drugs are widespread (Habsari, Rahardjo, Rahmah, \& Handoyo, 2007; Indonesian National AIDS Commission, 2014; Sari \& Nurmaya, 2009; Spooner et al., 2010). According to national harm reduction program data, $22 \%$ of women and $7 \%$ of men who inject drugs and live with HIV reported sharing needles and syringes in the preceding week, despite accessing harm reduction services during that period (Blogg, 2012). To develop a commensurate HIV response 
and optimise existing harm reduction services, it is vital to identify the factors driving HIV-related injection risk in this under-researched population.

Studies conducted with women who inject drugs in high-income countries suggest that one such factor may be intimate partner violence (IPV) (Gilbert et al., 2015). Indeed, extensive research to date has offered insight into how IPV contributes to elevated sexual HIV risks among drug-using women in North America (Braitstein et al., 2003; Strathdee et al., 1997; Wagner et al., 2009). Such risks include engaging in unprotected vaginal and anal sex, contracting sexually transmitted infections, having multiple partners, and trading sex for money, drugs, and shelter (El-Bassel et al., 2007; El-Bassel, Gilbert, Wu, Go, \& Hill, 2005). However, fewer studies have explored the relationship between IPV and risks associated with unsafe injecting drug use, and those that have are largely conducted in North America (Lorvick, Martinez, Gee, \& Kral, 2006; Strathdee et al., 1997; Wagner et al., 2009). Evidence from multiple settings indicates that women are more likely to share injecting equipment than men (Roberts, Mathers, \& Degenhardt, 2010; Sherman, Latkin, \& Gielen, 2009; Strathdee et al., 1997). Moreover, women are more likely to engage in unsafe injecting practices within sexual relationships with other persons who inject drugs than in other social relationships (Bruneau et al., 2001; Cleland et al., 2007; Davies, Dominy, Peters, \& Richardson, 1996; Hunter, Donoghoe, Stimson, Rhodes, \& Chalmers, 1995). Several studies, all conducted in the U.S., have established a significant association between IPV and needle/syringe sharing and borrowing (Braitstein et al., 2003; Strathdee et al., 1997; Wagner et al., 2009). Specifically, IPV can elevate women's HIV risk by establishing a dynamic of control, fear and submission that inhibits the ability to negotiate safe behaviours (Maman, Campbell, Sweat, \& Gielen, 2000). However, existing research remains limited. Among studies that have addressed this topic, the majority assessed lifetime history of sexual violence, including childhood abuse. Thus far, such research has not accounted for recent IPV or for the independent effects of different dimensions of IPV 
(e.g., psychological, physical, and sexual) on unsafe injecting practices. Moreover, existing research largely focuses on women in drug treatment or other health care settings, thus producing findings that may not be generalisable to community samples of women who inject drugs. A recent systematic review found that East and South-East Asia is home to the largest absolute number of women who inject drugs (828,000; range: $578,000-1,119,000)$, representing over $25 \%$ of the global female injecting drug user population (Degenhardt et al., 2017). Yet existing studies addressing the links between IPV and HIV risk remain geographically limited to high-income regions, particularly North America (Gilbert et al., 2015). Thus there is an urgent need to explore the effects of different dimensions of IPV on unsafe injecting behaviours in this vulnerable key population in Asia.

Understanding the interplay between IPV and HIV-related injection risk behaviours is crucial for informing interventions that address HIV vulnerability among women who use drugs in the region. This study aims to address this essential research gap by investigating whether different forms of IPV - psychological abuse, physical and/or injurious assault, and forced sex (rape) are associated with higher rates of unsafe injecting practices (i.e. receptive syringe sharing) in a sample of women who inject drugs in Indonesia.

\section{METHODS}

\section{Study design and population}

This study combined in-depth formative research with results from a quantitative survey based on a respondent-driven sample. Formative research conducted prior to the quantitative study comprised of four focus group discussions with members of the target population $(n=39)$ and key informant interviews with policy-makers, service providers, and community-based organisations in the substance use and HIV sectors. In addition to gathering information on the 
social networks of injection-drug using women, formative research also helped identify subpopulations of interest to guide the selection of initial recruits, inform the study instrument, and determine appropriate incentives.

The community of women who inject drugs was actively engaged throughout the development, implementation, and dissemination of this project. To ensure that all study procedures were sensitive to the needs of the community, three consultations with key population networks and community-based organisations were convened. A community advisory group comprised of women with an injecting drug use background was established to advise the research team throughout study implementation. Furthermore, a community consultation convened post-data collection guided the interpretation of findings and the formulation of a dissemination plan.

Between September 2014 and June 2015, 731 women were recruited from two sites in Indonesia: 1) Greater Jakarta, an administrative region with over 30 million inhabitants that includes Indonesia's capital Jakarta and adjacent metropolitan areas Bogor, Depok, Tangerang and Bekasi; and 2) Bandung, the provincial capital of West Java, and home to 8 million people. Study sites were selected with reference to their sizeable populations of people who inject drugs, and the substantial HIV burden shouldered by this group (Ministry of Health, 2012).

Women were eligible for the study if they were 18 years of age or older, injected any illegal or illicit drugs within the past 12 months, reported living in one of the study catchment areas, had a valid referral from an existing study participant, and were willing and able to provide informed consent.

Respondent-driven sampling (RDS) was used to recruit participants. RDS is an established, modified chain-referral method that employs statistical weighting to produce less biased estimates (Heckathorn, 1997). Conducting research with "hidden" or hard-to-reach groups such as people who inject drugs is often problematic because there may not be an adequate 
sampling frame (McCreesh et al., 2012). Since injecting drug use is a highly stigmatised activity and an illegal act with harsh penalties in Indonesia (Lai, Asmin, \& Birgin, 2013), reaching women who use drugs is challenging. Relative to men who inject drugs, women are more stigmatised and discriminated against by health services, the general community, peers, and family, which drives them to restrict their contact with service providers (Spooner et al., 2015). RDS addresses this challenge by facilitating access to hard-to-reach, networked groups via peer-to-peer referral (L. G. Johnston, Sabin, Mai, \& Pham, 2006; Kendall et al., 2008). RDS analytic methods produce more representative samples than commonly used snowballing techniques by reducing biases that result from network-based sampling via adjustment for differentials in network size and rates of recruitment across groups (Heckathorn, 2002; Salganik \& Heckathorn, 2004).

To commence recruitment, a diverse group of 20 seeds - heterogeneous by geography, age, socio-economic status, known HIV status, and levels of risk behaviour - was selected with guidance from the formative assessment and the community advisory group. A greater number of seeds was selected in Jakarta given its substantially larger geographical catchment area and number of inhabitants compared to Bandung. Initial recruits were asked to refer up to three eligible peers to the study, who, in turn, enlisted the next wave of participants. Recruitment continued in sequential waves until the desired sample size was attained. Assuming a $36 \%$ HIV prevalence (Indonesian National AIDS Commission, 2012), and a design effect of 2 (Salganik, 2006), the study required a minimum sample size of 709 for estimating the expected proportion with $5 \%$ absolute precision, $80 \%$ power, and $95 \%$ confidence.

\section{Procedures}

In response to the formative research finding that women would face multiple challenges attending interviews at a fixed site - as is standard practice in RDS studies - this study used 
mobile-site interviewing (L. G. Johnston, 2008; Platt, Luthra, \& Frere-Smith, 2015). Potential participants were instructed to contact the research team by phone or text message to arrange an interview at a location convenient for them. Questionnaires on self-reported behaviour were administered by trained female peer fieldworkers. Information was collected conducted in the local language (i.e. Bahasa Indonesia) using tablets equipped with Open Data Kit, an opensource data collection and management application operating on mobile devices (Hartung et al., 2010). As part of the RDS process, participants received a primary incentive of 75,000 Indonesian Rupiah ( USD \$5) for participating in the interview and a secondary incentive of 25,000 Indonesian Rupiah ( USD \$2) per eligible peer recruited. Each recruit was provided with a unique identifier and recorded in SyrEx2, a monitoring and evaluation tool developed by drug service providers (Alliance for Public Health, 2011).

\section{Ethical considerations}

Drug use in Indonesia is illegal and harshly prosecuted (Lai et al., 2013). This made the present study particularly sensitive and required additional care to protect participants. Participation was voluntary and data collected were anonymous. All participants were provided with a plainlanguage information sheet describing the nature of the study, limits to confidentiality, and explicit statements on participants' right to withdraw at any time. Informed consent forms were subsequently read aloud by the interviewer to ensure participants could make a fully informed decision, regardless of literacy level. Strict confidentiality was maintained, except where women requested assistance or referrals to health and support services. In the case that information disclosed suggested that a participant was at risk of significant harm (e.g. severe violence) the interviewer discussed concerns with the participant and offered service referrals. Following interviews, participants were provided with harm reduction materials and a directory of voluntary HIV counselling and testing services, sexual and reproductive health services, 
paralegal support and services for survivors of violence in the area. Ethical protocols were approved by the Central University Research Ethics Committee at Oxford University (ref no: SSD/CUREC2/13-23) and the Ethics Board of Atma Jaya University (ref no: 1114/II/LPPMPM.10.05/11/2013).

\section{Measurement}

Receptive syringe sharing was measured using four items from the Blood-Borne Virus Transmission Risk Assessment Questionnaire (BBV-TRAQ), a validated instrument that captures the frequency of injecting, sexual and other skin penetration risk practices in the previous 30 days (Fry \& Lintzeris, 2002). The BBV-TRAQ has been used extensively by governmental and community-based harm reduction and drug treatment programs (Wijoyo, Sarasvita, \& Rachman, 2014) and research studies in Indonesia (Iskandar et al., 2010; Wijoyo et al., 2014). Items assessed included: "In the last month, how many times have you injected with another person's used needle/syringe?"; "In the last month, how many times have you injected with a needle/syringe after another person has already injected some of its contents?"; "In the last month, how many times have you received a needle-stick/prick from another person's used needle/syringe?" and "In the last month, how many times have you re-used a needle/syringe taken out of a shared disposal/sharps container?" To achieve a higher sensitivity of the measure, affirmative responses (i.e., never, once, twice, $3-5$ times, $6-10$ times, > 10 times) were dichotomised to "any" or "no past-month receptive syringe sharing".

Intimate partner violence was assessed using items from the Revised Conflict Tactics Scale short form (CTS2S) (Strauss \& Douglas, 2004). The reliability of the CTS2S for this sample was Cronbach's $\alpha=0.85$. The following items were used for past-year IPV: psychological abuse ("My partner insulted or swore or shouted or yelled at me," "My partner destroyed something belonging to me or threatened to hit me"); physical assault ("My partner pushed, shoved, or 
slapped me," "My partner punched or kicked or beat-me-up"); injurious physical assault ("I had a sprain, bruise, or small cut, or felt pain the next day because of a fight with my partner," "I went see a doctor or needed to see a doctor because of a fight with my partner"); and forced sex or rape ("My partner used force, like hitting, holding down, or using a weapon, to make me have sex"). For each IPV dimension, responses were summed and dichotomised into any and no past-year violence victimisation. Scores for physical and injurious violence were combined since the specific items on the CTS2 physical and injurious subscales describe similar types of intimidation and control.

Informed by literature review and formative assessment, several potentially confounding sociodemographic and drug-related variables were assessed. Socio-demographic variables included: recruitment site, age, education level, employment status, relationship status, individual monthly income, housing status, and having dependent children in the household or other dependents for whom the participant is responsible. Individual monthly income was classified as being either below or above the average national monthly income in Indonesia (i.e. IDR 3.8 million/285 USD) (Statistics Indonesia, 2013). Housing status was assessed by asking participants about their current living arrangements. Unstable housing/homelessness referred to living on the street, including in public spaces (i.e. rail station, parks) or in temporary or transitional accommodation, such as a friend's home. Stable housing included residing in the family home, rental house or apartment, or long-term single-room accommodation (koskosan).

Participants also provided data on drug-related factors. These included age of injecting initiation, duration of injecting (Cleland et al., 2007), type of substance injected in the previous year (Stoicescu, Sari, \& Esteria-Tobing, 2011), intimate partner's injecting drug use status (Shaw, Shah, Jolly, \& Wylie, 2007), and whether women usually injected drugs together with an intimate partner (Tortu, McMahon, Hamid, \& Neaigus, 2003). Participants were also asked 
whether they had knowledge of their HIV status. All measures were based on self-report.

\section{Statistical analysis}

All analyses were conducted using Stata 14.2 (StataCorp, College Station, TX). Data analysis consisted of four steps.

First, population proportions and 95\% Cls and RDS network characteristics were calculated for outcome and analysis variables using the RDS add-on package in Stata (Schonlau \& Liebau, 2012), which applies the RDS-II estimator to produce weighted estimates (Volz \& Heckathorn, 2008). Network characteristics were calculated separately for the two survey sites. Network connectivity was assessed by asking: "(1) How would you best describe your relationship to your recruiter, i.e., the person who referred you to this study?" Participants' degree was measured using the following two questions: "(1) How many female friends or acquaintances do you know (you know their name and they know yours), who have injected drugs in the past year, are 18 years or older, and reside in Greater Jakarta or Bandung, and who you would be able to contact right now?" and "(2) How many of these women have you seen in the past month?" For this study, the standard social network question specifying a given timeframe (e.g. past month) in which participants had seen their peers was replaced with a question on participants' present ability to contact those in their network. Since interview appointments were scheduled by phone or text message, the research team deemed that the latter more accurately reflected the number of recruits participants were likely to recruit for this survey.

Seed dependence was assessed is by evaluating convergence, which refers to the required referral chain length (i.e. recruitment depth) necessary to reach sampling equilibrium (Volz \& Heckathorn, 2008). Since RDS recruitment starts with purposively selected seeds, and seeds may or may not accurately represent the underlying network structure of the target population, it is possible that the RDS recruitment process does not reach all sub-populations in a network. 
Consequently, the resulting sample may be more representative of the characteristics of the seeds rather than the characteristics of the target population, resulting in a form of selection bias (Tyldum \& Johnston, 2014). If the required recruitment depth for a given variable is smaller than the longest chain in the sample, then the final sample will be independent of the seeds and convergence has been reached. Differential recruitment activity (i.e. the relative connectedness of one sub-population within the sample with another) was measured by comparing participants' degrees and level of homophily, and testing for bottlenecks (Lisa G. Johnston \& Sabin, 2010). Homophily was calculated by comparing the estimated proportion of in-group ties within sample recruitment patterns with affiliation patterns that would result from random mixing. We referred to the homophily index proposed by Heckathorn, which contains values on a scale from -1.0 to 1.0 , with scores close to 0 indicating random recruitment and scores higher than 0.3 (or -0.3) indicating substantial in-group contact (Heckathorn, 2002). The presence of bottlenecks, which indicate the absence of personal links between different subgroups in a population, was assessed using network graphs produced with NetDraw (Borgatti, 2002). A severe bottleneck was observed for the two survey sites, such that all participants were clustered in either Greater Jakarta or Bandung, forming two isolated geographical components with minimal across-group recruitment (see Figure 1, Supplementary Digital File) (L. G. Johnston \& Luthra, 2014). Although the RDS estimators are designed to adjust for such biases to a certain extent, the presence of severe bottlenecks can add variance to a sample and produce unstable estimates (Gile, Johnston, \& Salganik, 2015). In the presence of a bottleneck, it is recommended that estimates are reported for each sub-group individually, rather than combining them into an overall estimate (Goel \& Salganik, 2010). Thus, population proportions and network characteristics were calculated separately for the two survey cities. However, in order to retain the power and confidence calculated in the initial sample size, the two unweighted samples from the two study sites were combined for the subsequent regression analyses (L. G. Johnston \& Luthra, 2014). 
Second, frequencies were calculated for all socio-demographic, background, and analysis variables using the aggregated dataset. Third, bivariate logistic regressions tested associations between IPV, and drug-related and socio-demographic factors, and receptive syringe sharing as the dependent variable, and guided the subsequent model selection. Variables associated with receptive syringe sharing at $p<0.1$ were retained in the multivariate models (Hosmer \& Lemenshow, 1989). Fourth, three sets of multivariate logistic regressions were estimated sequentially with psychological abuse, physical and/or injurious assault, and forced sex. All multivariate analyses controlled for city differences and significant covariates from the bivariate regressions. These included: injection drug type, survey city, housing status, relationship status, and having dependent children or other dependents. A final multivariate logistic regression model included all IPV dimensions (physical, psychological, and forced sex) and significant covariates.

\section{RESULTS}

\section{Respondent-driven sample characteristics}

This study recruited 731 women in total, using 18 seeds and 554 recruits in Greater Jakarta $(n=572)$ and 2 seeds and 157 recruits in Bandung $(n=159)$. Seed participant characteristics are summarised in Table 1. Of 20 seeds, only one seed $(Q)$, in Greater Jakarta, failed to recruit any participants. Overall, 15 of 20 seeds successfully propagated five or more waves of recruitment. Five seeds, two in Bandung (E, F) and three in Greater Jakarta $(H, J, R)$, generated $54 \%(n=391)$ of the total sample combined across the two survey cities. The largest recruitment chain reached up to 11 waves and contained 105 participants in Greater Jakarta, and 8 waves with 98 participants in Bandung. The largest recruitment chain accounted for $14 \%$ of referrals, such that no one chain dominated the sample. Recruitment referral chains for this sample are visually illustrated in Figure 1. 


\section{[INSERT TABLE 1]}

The required referral chain length until convergence was $2-4$ waves, which was smaller than the largest referral chain (8 waves) for Bandung, and 3-4 recruitment waves, which was smaller than the largest referral chain (11 waves), for Greater Jakarta.

The majority of participants in Greater Jakarta $(n=550 ; 96.2 \%)$ and Bandung $(n=157 ; 98.7 \%)$ were referred to the study by a friend. Two participants in Jakarta $(0.4 \%)$ were referred by an acquaintance, one by a female intimate partner $(0.2 \%)$, and one by a relative $(0.2 \%)$. The mean degree was $4.7(\mathrm{SD}=4.2$, range 1-35) in Greater Jakarta, and $3.9(\mathrm{SD}=2.0$, range 1-21) in Bandung. No considerable differentials in women's mean degrees were observed for Bandung. There were demonstrated differentials in personal degrees for receptive syringe sharing in Greater Jakarta, resulting in some participants having a greater potential to recruit peers with similar characteristics to them. Women who engaged in past-month receptive syringe sharing had an average degree of 6.67 , as compared to an average degree of 4.23 among those who did not share syringes during that period, suggesting that the former group were overrepresented in this sample.

All tested variables showed low homophily across the two study sites, with the exception of one socio-demographic variable (i.e. age). Women 24 years of age or younger in Bandung tended to over-recruit other young women $32 \%$ of the time $(\mathrm{H}=0.32)$, and at random only $68 \%$ of the time.

[INSERT FIGURE 1 - PLEASE USE COLOUR FOR PRINT] 


\section{Overview of injecting practices and exposure to IPV victimisation, by city}

Table 2 displays RDS-weighted estimations and 95\% confidence intervals $(\mathrm{Cl})$ for injecting risk outcomes and IPV victimisation variables, by survey city. Overall, Bandung had a higher prevalence of HIV-related injecting risk practices relative to Greater Jakarta. The proportion of women engaging in one or more past-month receptive syringe sharing practices in Bandung was three times $(35.5 \% ; 95 \% \mathrm{Cl}=28.4,43.2)$ that of Greater Jakarta $(10.8 \% ; 95 \% \mathrm{Cl}=8.8,13.1)$. In the preceding month, $26.6 \%(95 \% \mathrm{Cl}=20.4,33.9)$ of participants in Bandung and $4.4 \%(95 \%$ $\mathrm{Cl}=3.0,6.3)$ in Greater Jakarta reported injecting drugs with someone else's used syringe. Furthermore, $17.3 \%(95 \% \mathrm{Cl}=12.6,23)$ of women in Bandung and $7.3 \%(95 \% \mathrm{Cl}=5.7,9.4)$ of women in Greater Jakarta received a needle-stick/prick from someone else's used needle/syringe in the same time period. The prevalence of re-using a needle/syringe from a shared disposal or sharps container was $18.6 \%(95 \% \mathrm{Cl}=13.5,25.1)$ in Bandung and $1.2 \%$ $(95 \% \mathrm{Cl}=0.06,2.3)$ in Greater Jakarta.

More than half of the women in both cities experienced past-year psychological IPV, with higher prevalence reported in Greater Jakarta $(58.8 \%$; $95 \% \mathrm{Cl}=54.7,62.8)$ than Bandung $(52.6 \%$; $95 \% \mathrm{Cl}=44.7,60.3)$. Past-year physical and/or injurious assault was reported by $38.8 \%(95 \%$

$\mathrm{Cl}=35.0,42.8)$ of women in Greater Jakarta and $42.2 \%(95 \% \mathrm{Cl}=34.8,50.0)$ of women in Bandung. Notably, the prevalence of forced sex (rape) was more than four times higher among women from Bandung (13.7\%; $95 \% \mathrm{Cl}=9.0,20.3)$ than women from Greater Jakarta (3.1\%; $95 \% \mathrm{Cl}=2.0,4.8)$.

[INSERT TABLE 2]

\section{Sociodemographic and drug-related characteristics}


Socio-demographic characteristics calculated on the unweighted, aggregated sample from the two cities, are displayed in Table 3. The majority of participants were under 35 years of age (64.7\%), with a mean age of 31.3 years ( $S D=5.10$ years; range: $18.0-44.6)$. $62.6 \%$ of women in the full sample were married or in a steady relationship, and $56.5 \%$ had children or other dependents. Nearly half of the women (44.3\%) were unemployed, and one in five $(20.2 \%)$ completed less than a high school education. Mean individual monthly income was IDR 4.3 million/USD 385 (SD=3.38). 5.3\% of women lived on the street or in unstable housing. Overall self-reported HIV prevalence was $46.7 \%$. Considering that $56.3 \%$ of the women were last tested for HIV more than 12 months prior to the survey and $16.1 \%$ never accessed HIV testing, actual undiagnosed HIV prevalence in the sample is likely to be higher.

Self-reported injection drug type in the sample is shown in Table 3. Women injected several types of drugs in the previous year, ranging from heroin only $(77.8 \%)$, to illicit pharmaceuticals only (5.3\%), and crystal meth (0.6\%). A substantial proportion of the sample $(16.3 \%)$ injected both heroin and pharmaceuticals. Among women exclusively injecting pharmaceuticals, the most commonly injected pharmaceutical was buprenorphine (93.8\%), an oral opioid antagonist used to treat opioid dependence, followed by illicit benzodiazepines (e.g. diazepam), commonly used to treat anxiety and depression, and opiate-based pain medications (e.g. codeine, tramadol) (6.2\%). Participants injected drugs for an average of 10.3 years $(S D=5.09$, range: 0.3-24.1). $6.4 \%$ of the women in the sample were new injectors (i.e. injecting for $\leq 2$ years). Mean age of injecting initiation was 21.2 years $(S D=4.28$, range: $12-37)$, with nearly one third (28.4\%) of participants initiating injecting drug use at 18 years or younger. The youngest reported age of initiation to injecting drug use was 12 years old. $52.1 \%$ of women had an intimate partner who also injected drugs. Nearly half of women in the sample $(43.5 \%)$ reported that they usually injected drugs together with an intimate partner. 


\section{[INSERT TABLE 3]}

\section{Associations between past-year IPV and receptive syringe sharing}

Results from bivariate analyses between variables from Table 3 and the receptive syringe sharing outcome are shown in Table 4. Elevated odds of receptive syringe sharing were associated with exposure to past-year psychological abuse $(\mathrm{OR}=2.37 ; 95 \% \mathrm{Cl}=1.59,3.53$; $\mathrm{p}<0.001)$, physical and/or injurious IPV $(\mathrm{OR}=2.43 ; 95 \% \mathrm{Cl}=1.69$, 3.50; $\mathrm{p}<0.001)$, and forced sex $(\mathrm{OR}=3.13 ; 95 \% \mathrm{Cl}=1.62,6.06 ; \mathrm{p}=0.001)$. Women were also more likely to engage in receptive syringe sharing if they resided in Bandung (versus Greater Jakarta) (OR=2.96; 95\% $\mathrm{Cl}=2.00,4.37 ; \mathrm{p}<0.001)$, were homeless or unstably-housed (vs stably-housed) (OR=3.13; $95 \% \mathrm{Cl}=1.62,6.06 ; \mathrm{p}=0.001)$, and injected pharmaceuticals only $(\mathrm{OR}=5.06 ; 95 \% \mathrm{Cl}=2.60$, 9.84; $p<0.001)$ or combination heroin and pharmaceuticals (vs. heroin only) $(O R=1.92 ; 95 \%$ $\mathrm{Cl}=1.22,3.03 ; \mathrm{p}=0.005)$. Women who were married or in a steady relationship $(\mathrm{OR}=0.53 ; 95 \%$ $\mathrm{Cl}=0.33,0.87 ; \mathrm{p}=0.011)$ and women with children or other dependents $(\mathrm{OR}=0.63 ; 95 \%$ $\mathrm{Cl}=0.44,0.90 ; \mathrm{p}=0.011$ ) were less likely to engage in receptive syringe sharing, compared with their single counterparts and women without dependents, respectively.

\section{[INSERT TABLE 4]}

Results of multivariate models for each dimension of IPV (models $1-3$ ) are displayed in Table 5. After adjusting for covariates significant at $p<0.1$ in bivariate analyses (i.e. survey city, injection drug type, relationship status, having children and or other dependents, and housing status), each form of IPV remained significantly associated with increased odds of receptive syringe sharing. In model 1, women who experienced psychological abuse were 2.7 more likely $(\mathrm{OR}=2.72 ; 95 \% \mathrm{Cl}=1.74,4.23 ; \mathrm{p}<0.001)$ to engage in receptive syringe sharing. Exposure to physical and/or injurious assault more than doubled the odds of receptive syringe sharing 
$(\mathrm{OR}=2.53 ; 95 \% \mathrm{Cl}=1.69,3.77 ; \mathrm{p}<0.001)$ (model 2). In model 3, experiencing past-year forced sex tripled the odds of engaging in receptive syringe sharing $(\mathrm{OR}=3.01 ; 95 \% \mathrm{Cl}=1.19,7.57$; $p=0.025)$. The following covariates remained significantly positively associated with receptive sharing in all three models: injecting pharmaceuticals only, homelessness and/or unstable housing, and residing in Bandung.

The final multivariate model (model 4, Table 5) included all three forms of IPV. After adjusting for significant covariates, psychological abuse $(\mathrm{OR}=1.86 ; 95 \% \mathrm{Cl}=1.06,3.24 ; \mathrm{p}=0.030)$ and physical and/or injurious assault $(\mathrm{OR}=1.73 ; 95 \% \mathrm{Cl}=1.04,2.89 ; \mathrm{p}=0.034)$ retained a statistically significant positive association with receptive syringe sharing. Forced sex did not remain significant in the final model $(\mathrm{OR}=1.11 ; 95 \% \mathrm{Cl}=0.51,2.41 ; \mathrm{p}=0.785)$. Additionally, women who injected illicit pharmaceuticals only $(\mathrm{OR}=3.58 ; 95 \% \mathrm{Cl}=1.66,7.69 ; \mathrm{p}=0.001)$, and homeless and/or unstably-housed women $(\mathrm{OR}=2.89 ; 95 \% \mathrm{Cl}=1.41,5.95 ; \mathrm{p}=0.004)$ had higher odds of engaging in receptive syringe sharing, relative to women who injected heroin only and to those with stable housing, respectively. Compared with their counterparts from Greater Jakarta, women from Bandung, West Java were more likely to engage in receptive syringe sharing $(\mathrm{OR}=2.33 ; 95 \% \mathrm{Cl}=1.40,3.90 ; \mathrm{p}=0.001)$.

\section{[INSERT TABLE 5]}

\section{DISCUSSION}

To our knowledge, this is the first quantitative study to investigate associations between different dimensions of IPV and unsafe injecting practices amongst women who inject drugs in Asia. This study found that a sizeable minority of women who inject drugs in Indonesia continue to engage in receptive syringe sharing, despite more than a decade of harm reduction interventions (Indonesian National AIDS Commission, 2014). In 2015, 5.8\% of people who 
inject drugs surveyed as part of national bio-behavioural HIV surveillance reported sharing needle-syringes in the previous week (Ministry of Health, 2015), compared with a rate nearly three times as high among women in this sample. These findings suggest that there remains a high potential for HIV infection among women who inject drugs and onward transmission to their injecting and sexual partners.

Furthermore, past-year rates of psychological abuse and physical and/or injurious violence in this sample were $8-22$ times higher than rates among Indonesian women in the general population (Statistics Indonesia, 2017). The prevalence of physical and/or injurious assault in this study was comparable and/or higher than rates found in community samples of women who inject drugs in other low- or middle-income countries in the region, such as India (17\%) and China (39.5\%) (Gu et al., 2014; India HIV/AIDS Alliance, 2011). While previous research has shown a link between IPV and elevated risk for HIV-related sexual risk behaviours among women who inject drugs, this is the first study in the region to suggest a similar link between IPV and unsafe injecting practices.

This study adds new evidence from a lower-middle income setting showing that psychological abuse and physical and/or injurious assault were independently associated with greater HIVrelated injecting risk, after controlling for other forms of IPV and socio-demographic factors. Previous research suggests that sharing injecting equipment within a sexual relationship can be associated with feelings of support, trust, love, intimacy and protection (MacRae \& Aalto, 2000; Roberts et al., 2010; Sherman et al., 2009; Simmons \& Singer, 2006), but also with male power and control (Barnard, 1993; Klee, 1993; Lazuardi et al., 2012; Spooner et al., 2010; Wagner et al., 2009). In the Indonesian context, qualitative research suggests that control both physical and psychological - is central to the role of intimate partnerships in the lives of many women who inject drugs. Submitting to men's wishes, including on occasions where there is a known HIV risk, is often viewed as a way of avoiding conflict, confrontation and, potentially, 
further violence (Spooner et al., 2010). Similar to findings showing that women in violent relationships are less able to negotiate condom use (El-Bassel et al., 2005; Panchanadeswaran et al., 2010), this study extends previous research from the U.S. by suggesting that they may also be less able to negotiate safer drug injection (Wagner et al., 2009). Such power imbalances and their consequences seem to persist despite availability of sterile needles and syringes. These findings underline the urgent need to integrate case-finding and support interventions aimed at identifying and addressing IPV among women who use drugs within existing HIV prevention programs.

Notably, women who exclusively injected pharmaceuticals, primarily buprenorphine, were significantly more likely to share and re-use needles and syringes than women who injected heroin only. This finding is at odds with results from an international review suggesting that buprenorphine injectors report lower rates of injecting equipment sharing and other HIV-related risk behaviours, compared with heroin injectors (Yokell, Zaller, Green, \& Rich, 2011). Medicallysupervised oral buprenorphine was introduced in Indonesia in 2002 as substitution therapy for the detoxification and maintenance of opioid-dependent persons. However, the management of buprenorphine administration by private doctors, combined with the absence of national guidelines until recently, may have increased buprenorphine's potential for diversion and illicit use. Significantly higher rates of injecting equipment sharing among women who inject pharmaceuticals in this study may be explained by increases in the diversion and illicit use of buprenorphine and other prescription drugs, coupled with the absence of comprehensive harm reduction programs targeting this sub-group of the drug-using population. Indeed, until recently, Indonesia's HIV prevention program has targeted heroin users, despite documented increases in the injection of illicit buprenorphine and other pharmaceuticals (Indonesian National AIDS Commission, 2014). Thus, this study's findings suggest that HIV prevention interventions in Indonesia would benefit from broadening their focus to include people who use multiple 
substances and drugs other than heroin.

Furthermore, unstable housing and homelessness were associated with greater HIV-related injection risk. Specifically, the odds of receptive syringe sharing were between $3-5$ times as high among women who were homeless or unstably housed, compared with women with stable housing. This finding extends research from high-income settings highlighting that precarious housing increases HIV-related risks among people who use drugs (Aidala, Cross, Stall, Harre, \& Sumartojo, 2005). Women's housing disadvantage may increase their HIV vulnerability by perpetuating gender power imbalances. For instance, many drug-using women living on the street resort to survival sex work to maintain their and/or their partner's drug supply and provide for dependents (Shannon et al., 2008). This increases women's risk of experiencing violence, and places them in high-risk sexual and injecting contexts where they may have limited negotiating power. Any effective HIV prevention strategy must include structural solutions such as enhanced housing and economic opportunities. Our data suggest that support toward housing and economic empowerment could be important tools for reducing HIV-related risk behaviours. Previous research in the U.S. shows that stable housing is associated with decreases in risky sexual and injecting behaviours (Aidala et al., 2005; Wenzel et al., 2009). Similarly, some economic enhancement initiatives for women who use drugs have been associated with a reduction in HIV risk behaviours (Pinkham, Stoicescu, \& Myers, 2012; Sherman, German, Cheng, Marks, \& Bailey-Kloche, 2006). Since the behaviours studied here are also risk factors for other blood borne viruses such as hepatitis B and C, structural interventions including housing support and economic empowerment could contribute to multiple prevention goals. Given that no such interventions have been tested among women who inject drugs in Indonesia to date, further research is needed to understand the multitude of risk environments shaping women's HIV vulnerability and develop appropriate and culturallyrelevant responses. 
Limitations include the cross-sectional nature of the study, which constrains the ability to make causal inferences. Second, self-reported data on injecting behaviours may be subject to social desirability bias. Women may be reluctant to report sharing of injecting equipment in a context where sterile needles and syringes are available. We attempted to improve reporting of HIV risk-taking by assuring confidentiality and anonymity, and by using female peer interviewers with an injecting drug use background. The latter strategy has been shown to provide greater opportunity to foster trust between participants and interviewers, thus improving the reliability of self-reported behaviours (Broadhead et al., 1998). Third, a secondary goal of this study was to generate representative prevalence estimates among women who inject drugs. RDS is based on the assumption that each sample comprises a single network component (Goel \& Salganik, 2010). This assumption was fulfilled at the city level, but not at the level of the combined sample from the two study sites. There is currently no consensus on whether separate network samples can be aggregated (L. G. Johnston \& Luthra, 2014). Current best practice is to test for bottlenecks, and if present, to conduct a sensitivity analysis by comparing several important variables for each of the two bottle-necked sub-samples (L. G. Johnston \& Luthra, 2014). If the estimates based on the two sub-samples are similar, the data can be combined and analysed as one sample. Since the two city sub-samples were severely bottlenecked, and substantial differences were observed in terms of estimated population proportions for the receptive syringe sharing outcome, RDS-adjusted estimates were reported separately for each city. However, in order to retain the power and confidence of the original calculated sample size, and because city differences can be controlled for in multivariate analyses, the full, unweighted dataset was used for the regression analyses. Therefore, aside from the city-level estimates, findings may not be representative according to the theoretical premises upon which RDS is based (Heckathorn, 2002). 
Despite these limitations, the present study has important implications. Reducing unsafe injection practices among people who inject drugs has been the target of numerous HIV prevention interventions implemented in Indonesia since the early 2000s (Morineau et al., 2012). Despite these interventions, an unacceptably high proportion of women continue to share and re-use injecting equipment. Existing harm reduction programmes aimed at reducing blood borne virus transmission among people who inject drugs in Indonesia should tailor their services to be more accessible to women (Malinowska-Sempruch, 2015). This could include creating women-only hours and child-friendly spaces within existing services, employing female peers, expanding mobile and other outreach-led health services, and integrating harm reduction, sexual and reproductive health and rights education, and violence prevention services into a "one-stop shop" model of service provision (Blankenship, Reinhard, Sherman, \& El-Bassel, 2015; Pinkham, Myers, \& Stoicescu, 2012). Furthermore, case-finding and IPV prevention and support programs should target women who use drugs. Potential settings amenable to violence prevention interventions among drug-using women are outpatient substance use treatment and community-based drug treatment services (Tirado-Munoz, Gilchrist, Lligona, Gilbert, \& Torrens, 2015). Case-finding interventions would be optimised by robust referral systems that enable effective referral to a diverse array of services, including legal advocacy and/or parenting and childcare support. Clearly, more effective public health responses to reduce violence and address unsafe injecting drug use amongst this highlyvulnerable population are urgently needed. 


\section{REFERENCES}

Aidala, A., Cross, J. E., Stall, R., Harre, D., \& Sumartojo, E. (2005). Housing status and HIV risk behaviors: Implications for prevention and policy. AIDS and Behaviour, 9(3), 251265.

Alliance for Public Health. (2011). Automated records management system in harm reduction programs: SyrEx2. Retrieved from Kiev: Ukraine:

Barnard, M. A. (1993). Needle sharing in context: Patterns of sharing among men and women injectors and HIV risks. Addiction, 88, 805-812.

Blankenship, K. M., Reinhard, E., Sherman, S. G., \& El-Bassel, N. (2015). Structural interventions for HIV prevention among women who use drugs: A global perspective. Journal of Acquired Immune Deficiency Syndromes, 69(2), S140-S145.

Blogg, S. (2012). Female injecting drug users: behaviour and service satisfaction survey among female clients of harm reduction services in Bali, Banten, DKI Jakarta, East Java, Central Java, West Java, Yogyakarta. Indonesian National AIDS Commission. Jakarta, Indonesia.

Borgatti, S. P. (2002). NetDraw software for network visualization. (Version 2.155). Lexington, Kentucky: Analytic Technologies.

Braitstein, P., Li, K., Tyndall, M., Spittal, P. M., O'Shaughnessy, M. V., Schilder, A., . . Schechter, M. T. (2003). Sexual violence among a cohort of injection drug users. Social Science and Medicine, 57(3), 561-569.

Broadhead, R. S., Heckathorn, D., Weakliem, D. L., Anthony, D. L., Madray, H., Mills, R. J., \& Hughes, J. (1998). Harnessing peer networking as an instrument for AIDS prevention: Results from a peer-driven intervention. Public Health Reports, 113(1), 42-57.

Bruneau, J., Lamothe, F., Soto, J., Lachance, N., Vincelette, J., Vassal, A., \& Franco, E. L. (2001). Sex-specific determinants of HIV infection among injection drug users in Montreal. Canadian Medical Association Journal, 164(6), 767-773.

Cleland, C. M., Des Jarlais, D. C., Perlis, T. E., Stimson, G., Poznyak, V., \& Group, W. H. O. P. I. D. I. C. S. (2007). HIV risk behaviors among female IDUs in developing and transitional countries. BMC Public Health, 7, 271.

Davies, A. G., Dominy, N. J., Peters, A. D., \& Richardson, A. M. (1996). Gender differences in HIV risk behaviour of injecting drug users in Edinburgh. AIDS Care, 8(5), 517-527. doi:10.1080/09540129650125489

Degenhardt, L., Peacock, A., Colledge, S., Leung, J., Grebely, J., Vickerman, P., . . Larney, S. (2017). Global prevalence of injecting drug use and sociodemographic characteristics and prevalence of $\mathrm{HIV}, \mathrm{HBV}$, and $\mathrm{HCV}$ in people who inject drugs: A multistage systematic review. The Lancet Global Health, 5(12), e1192-e1207. doi:10.1016/s2214109x(17)30375-3

Des Jarlais, D. C., Feelemyer, J. P., Modi, S. N., Arasteh, K., \& Hagan, H. (2012). Are females who inject drugs at higher risk for HIV infection than males who inject drugs: An international systematic review of high seroprevalence areas. Drug and Alcohol Dependence, 124(1-2), 95-107. doi:10.1016/j.drugalcdep.2011.12.020

El-Bassel, N., Gilbert, L., Wu, E., Chang, M., Gomes, C., Vinocur, D., \& Spevack, T. (2007). Intimate partner violence prevalence and HIV risks among women receiving care in emergency departments: Implications for IPV and HIV screening. Emergency Medicine Journal, 24(4), 255-259. doi:10.1136/emj.2006.041541 
El-Bassel, N., Gilbert, L., Wu, E., Go, H., \& Hill, J. (2005). Relationship between drug abuse and intimate partner violence: A longitudinal study among women receiving methadone. American Journal of Public Health, 95(3), 465-470. doi:10.2105/AJPH.2003.023200

El-Bassel, N., \& Strathdee, S. A. (2015). Women who use or inject drugs: An action agenda for women-specific, multilevel, and combination HIV prevention and research. Journal of Acquired Immune Deficiency Syndromes, 69(2), S182-S190.

Fry, C. L., \& Lintzeris, N. (2002). Psychometric properties of the Blood-borne Virus Transmission Risk Assessment Questionnaire (BBV-TRAQ). Addiction, 98, 171-178.

Gilbert, L., Raj, A., Hien, D., Stockman, J., Terlikbayeva, A., \& Wyatt, G. (2015). Targeting the SAVA (Substance Abuse, Violence, and AIDS) syndemic among women and girls: A global review of epidemiology and integrated interventions. Journal of Acquired Immune Deficiency Syndromes, 69(2), S118-S127.

Gile, K. J., Johnston, L. G., \& Salganik, M. J. (2015). Diagnostics for respondent-driven sampling. Journal of the Royal Statistical Society, 178(1), 241-269.

Goel, S., \& Salganik, M. J. (2010). Assessing respondent-driven sampling. Proceedings of the National Academy of Sciences, 107(15), 6743-6747. doi:10.1073/pnas.1000261107

Gu, J., Bai, Y., Lau, J. T., Hao, Y., Cheng, Y., Zhou, R., \& Yu, C. (2014). Social environmental factors and condom use among female injection drug users who are sex workers in China. AIDS and Behaviour, 18 Suppl 2, S181-191. doi:10.1007/s10461-013-0434-z

Habsari, R., Rahardjo, T., Rahmah, A., \& Handoyo, P. (2007). Perempuan-perempuan di langkar Napza: Laporan kajian kebutuhan pengguna Napza suntik perempuan di delapan kota di Indonesia, 2007. Retrieved from Jakarta, Indonesia:

Hartung, C., Lerer, A., Anokwa, Y., Tseng, C., Brunette, W., \& Borriello, G. (2010). Open Data Kit: Tools to build information services for developing regions. Paper presented at the 4th ACM/IEEE International Conference on Information and Communication Technologies and Development, London, United Kingdom.

Heckathorn, D. (1997). Respondent-driven sampling: A new approach to the study of hidden populations. Social Problems, 44(2), 174-199.

Heckathorn, D. (2002). Respondent-driven sampling II: Deriving valid populations estimates from chain-referral samples of hidden populations. Social Problems, 49(1), 11-34.

Hosmer, D. W., \& Lemenshow, S. (1989). Applied logistic regression. New York, New York: Wiley.

Hunter, G. M., Donoghoe, M. C., Stimson, G. V., Rhodes, T., \& Chalmers, C. P. (1995). Changes in the injecting risk behaviour of injecting drug users in London, 1990-1993. AIDS, 9(5), 493-501.

India HIV/AIDS Alliance. (2011). In the Shadows: The Chanura Kol baseline study on women who inject drugs in Manipur, India. Retrieved from New Delhi, India:

Indonesian National AIDS Commission. (2012). Republic of Indonesia Country Report on the Follow up to the Declaration of Commitment on HIV/AIDS (UNGASS): Reporting period 2010-2011. Retrieved from Jakarta, Indonesia:

Indonesian National AIDS Commission. (2014). Global AIDS Progress Reporting: Indonesia Country Progress Report 2014. Retrieved from Jakarta, Indonesia:

Iskandar, S., Basar, D., Hidayat, T., Siregar, I. M. P., Pinxten, L., van Crevel, R., . . De jong, C. A. D. (2010). High risk behavior for HIV transmission among former injecting drug users: A survey from Indonesia. BMC Public Health, 10(472), 1-7. 
Johnston, L. G. (2008). Behavioural surveillance: Introduction to respondent driven sampling (training manual). Retrieved from

Johnston, L. G., \& Luthra, R. (2014). Analyzing data in RDS. In G. Tyldum \& L. G. Johnston (Eds.), Applying Respondent Driven Sampling to Migrant Populations: Lessons from the Field. London, United Kingdom: Palgrave Pivot.

Johnston, L. G., \& Sabin, K. (2010). Sampling hard-to-reach populations with respondent driven sampling. Methodological Innovations Online, 5(2), 38-48. doi:10.4256/mio.2010.0017

Johnston, L. G., Sabin, K., Mai, T. H., \& Pham, T. H. (2006). Assessment of respondent driven sampling for recruiting female sex workers in two Vietnamese cities: Reaching the unseen sex worker. Journal of Urban Health, 83(6 Suppl), i16-28. doi:10.1007/s11524006-9099-5

Kendall, C., Kerr, L. R., Gondim, R. C., Werneck, G. L., Macena, R. H., Pontes, M. K., . . McFarland, W. (2008). An empirical comparison of respondent-driven sampling, time location sampling, and snowball sampling for behavioral surveillance in men who have sex with men, Fortaleza, Brazil. AIDS and Behaviour, 12(4 Suppl), S97-104. doi:10.1007/s10461-008-9390-4

Klee, H. (1993). HIV risks for women drug injectors: Heroin and amphetamine users compared. Addiction, 88, 1055-1062.

Lai, G., Asmin, F., \& Birgin, R. (2013). Drug policy in Indonesia. Retrieved from Bangkok, Thailand:

Larney, S., Mathers, B. M., Poteat, T., Kamarulzaman, A., \& Degenhardt, L. (2015). Global epidemiology of HIV among women and girls who use or inject drugs: Current knowledge and limitations of existing data. Journal of Acquired Immune Deficiency Syndromes, 69(2), S100-S109.

Lazuardi, E., Worth, H., Saktiawati, A. M., Spooner, C., Padmawati, R., \& Subronto, Y. (2012). Boyfriends and injecting: the role of intimate male partners in the life of women who inject drugs in Central Java. Culture, Health \& Sexuality, 14(5), 491-503. doi:10.1080/13691058.2012.671960

Lorvick, J., Martinez, A., Gee, L., \& Kral, A. H. (2006). Sexual and injection risk among women who inject methamphetamine in San Francisco. Journal of Urban Health, 83(3), 497-505. doi:10.1007/s11524-006-9039-4

MacRae, R., \& Aalto, E. (2000). Gendered power dynamics and HIV risk in drug-using sexual relationships. AIDS Care, 12(4), 505-515. doi:10.1080/09540120050123909

Malinowska-Sempruch, K. (2015). What interventions are needed for women and girls who use drugs? A global perspective. Journal of Acquired Immune Deficiency Syndromes, 69(2), S96-S97.

Maman, S., Campbell, S., Sweat, M. D., \& Gielen, A. C. (2000). The intersections of HIV and violence: Directions for future research and interventions. Social Science \& Medicine, 50(4), 459-478.

McCreesh, N., Frost, S. D., Seeley, J., Katongole, J., Tarsh, M. N., Ndunguse, R., . . White, R. G. (2012). Evaluation of respondent-driven sampling. Epidemiology, 23(1), 138-147. doi:10.1097/EDE.0b013e31823ac17c

Ministry of Health. (2012). Size estimate workbooks.

Ministry of Health. (2015). Integrated Biological and Behavioural Survey. Jakarta, Indonesia: Ministry of Health. 
Morineau, G., Bollen, L. J., Syafitri, R. I., Nurjannah, N., Mustikawati, D. E., \& Magnani, R. (2012). HIV prevalence and risk behaviours among injecting drug users in six indonesian cities: Implications for future HIV prevention programs. Harm Reduction Journal, 9, 37. doi:10.1186/1477-7517-9-37

Panchanadeswaran, S., Frye, V., Nandi, V., Galea, S., Vlahov, D., \& Ompad, D. (2010). Intimate partner violence and consistent condom use among drug-using heterosexual women in New York City. Women Health, 50(2), 107-124. doi:10.1080/03630241003705151

Pinkham, S., Myers, B., \& Stoicescu, C. (2012). Developing effective harm reduction services for women who inject drugs. In C. Stoicescu (Ed.), Global state of harm reduction 2012 (Vol. 2, pp. 125-136). London, United Kingdom: International Harm Reduction Association.

Pinkham, S., Stoicescu, C., \& Myers, B. (2012). Developing effective health interventions for women who inject drugs: Key areas and recommendations for program development and policy. Advances in Preventive Medicine, 2012, 1-10. doi:10.1155/2012/269123

Platt, L., Luthra, R., \& Frere-Smith, T. (2015). Adapting chain referral methods to sample new migrants. Demographic Research, 33, 665-700. doi:10.4054/DemRes.2015.33.24

Roberts, A., Mathers, B., \& Degenhardt, L. (2010). Women who inject drugs: A review of their risks, experiences and needs. Retrieved from Sydney, Australia:

Salganik, M. J. (2006). Variance estimation, design effects, and sample size calculations for respondent-driven sampling. Journal of Urban Health, 83(6 Suppl), i98-112. doi:10.1007/s11524-006-9106-X

Salganik, M. J., \& Heckathorn, D. D. (2004). Sampling and estimation in hidden populations using respondent-driven sampling. Sociological Methodology, 34, 193-239.

Sari, S. W., \& Nurmaya, B. V. (2009). Pengalaman perempuan pengguna narkotika suntik (Penasun) dalam mengakses layanan harm reduction: sebuah kajian cepat. Retrieved from Jakarta, Indonesia

Schonlau, M., \& Liebau, E. (2012). Respondent driven sampling. The Stata Journal, 12(1), 7293.

Shannon, K., Kerr, T., Allinott, S., Chettiar, J., Shoveller, J., \& Tyndall, M. W. (2008). Social and structural violence and power relations in mitigating HIV risk of drug-using women in survival sex work. Social Science and Medicine, 66(4), 911-921. doi:10.1016/j.socscimed.2007.11.008

Shaw, S. Y., Shah, L., Jolly, A. M., \& Wylie, J. L. (2007). Determinants of injection drug user (IDU) syringe sharing: The relationship between availability of syringes and risk network member characteristics in Winnipeg, Canada. Addiction, 102(10), 1626-1635. doi:10.1111/j.1360-0443.2007.01940.x

Sherman, S. G., German, D., Cheng, Y., Marks, M., \& Bailey-Kloche, M. (2006). The evaluation of the JEWEL project: An innovative economic enhancement and HIV prevention intervention study targeting drug using women involved in prostitution. AIDS Care, 18(1), 1-11.

Sherman, S. G., Latkin, C. A., \& Gielen, A. C. (2009). Social factors related to syringe sharing among injecting partners: A focus on gender. Substance Use and Misuse, 36(14), 21132136. doi:10.1081/ja-100108439

Simmons, J., \& Singer, M. (2006). I love you ... and heroin: Care and collusion among drugusing couples. Substance Abuse Treatment, Prevention, and Policy, 1(7), 1-13. doi:10.1186/1747-597X-1- 
Spooner, C., Saktiawati, A. M., Lazuardi, E., Worth, H., Subronto, Y., \& Padmawati, R. (2015). Impacts of stigma on HIV risk for women who inject drugs in Java: A qualitative study. International Journal of Drug Policy, 26(12), 1244-1250.

Spooner, C., Saktiawati, A. M. I., Lazuardi, E., Worth, H., Subronto, Y. W., \& Padmawati, R. S. (2010). Women who inject drugs in central Java and HIV risk. Retrieved from Sydney, Australia:

Statistics Indonesia. (2013). Census Indonesia: Social and population data. Jakarta, Indonesia.

Statistics Indonesia. (2017). Prevalence of violence against women in Indonesia: Results from the 2016 Women's Life Experience Survey. Jakarta, Indonesia.

Stoicescu, C., Sari, S. W., \& Esteria-Tobing, N. (2011). Risk and protective factors for HIV transmission among women who inject drugs in Jakarta, Indonesia: An exploratory study. Paper presented at the 10th International Congress on AIDS in Asia and the Pacific (ICAAP). Busan, South Korea. Oral Presentation retrieved from

Stone, K. A. (2016). Global State of Harm Reduction. Retrieved from London, United Kingdom:

Strathdee, S. A., Patrick, D. M., Archibald, C. P., Ofner, M., Cornelisse, P. G. A., Rekart, M., . . O'Shaughnessy, M. V. (1997). Social determinants predict needle-sharing behaviour among injecting drug users in Vancouver, Canada. Addiction, 92(10), 1139-1347.

Strauss, M. A., \& Douglas, E. M. (2004). A short form of the Revised Conflict Tactics Scales, and typologies for severity and mutuality. Violence and Victims, 19(5), 507-520.

Tirado-Munoz, J., Gilchrist, G., Lligona, E., Gilbert, L., \& Torrens, M. (2015). A group intervention to reduce intimate partner violence among female drug users: Results from a randomized controlled pilot trial in a community substance abuse center. Adicciones, 27(3).

Tortu, S., McMahon, J. M., Hamid, R., \& Neaigus, A. (2003). Women's drug injection practices in east Harlem: An event analysis in a high-risk community. AIDS and Behaviour, 7(3), 317-328.

Tyldum, G., \& Johnston, L. G. (2014). Applying Respondent Driven Sampling to Migrant Populations: Lessons from the Field. London, United Kingdom: Palgrave Macmillan.

UNAIDS. (2014). The Gap Report. Retrieved from Geneva, Switzerland:

Volz, E., \& Heckathorn, D. (2008). Probability based estimation theory for respondent driven sampling. Journal of Official Statistics, 24(1), 79-97.

Wagner, K. D., Hudson, S. M., Latka, M. H., Strathdee, S. A., Thiede, H., Mackesy-Amiti, M. E., \& Garfein, R. S. (2009). The effect of intimate partner violence on receptive syringe sharing among young female injection drug users: An analysis of mediation effects. AIDS and Behaviour, 13(2), 217-224. doi:10.1007/s10461-007-9309-5

Wenzel, S. L., Green, H. D., Jr., Tucker, J. S., Golinelli, D., Kennedy, D. P., Ryan, G., \& Zhou, A. (2009). The social context of homeless women's alcohol and drug use. Drug and Alcohol Dependence, 105(1-2), 16-23. doi:10.1016/j.drugalcdep.2009.05.026

Wijoyo, E., Sarasvita, R., \& Rachman, A. (2014). Evaluation process for community-based drug treatment program in Indonesia. Paper presented at the National Institute on Drug Abuse International Forum, San Juan, Puerto Rico.

Yokell, M. A., Zaller, N. D., Green, T. C., \& Rich, J. D. (2011). Buprenorphine and buprenorphine/naloxone diversion, misuse, and illicit use: An international review. Current Drug Abuse Review, 4(1), 28-41. 